\title{
STUDY INTERIONIC ATTRACTION OF ANIONIC DYES BY ELECTROLYTIC CONDUCTIVITY MEASUREMENT
}

\author{
Elshimaa H. Gomaa* \\ Chemistry Department, Faculty of Science, (Girls), Al-Azhar University Nasr City, Cairo, Egypt \\ *Corresponding Author: Alshimaa@azhar.edu.eg
}

\begin{abstract}
Measurements of conductivity in aqueous solution are recommended for studying the behavior of some dyes. The conductivity of two azo dyes C.I. Acid Red 151 (AR 151) and C.I. Mordant green 17 (MG17) have been studied. The ionization degree, $\alpha$ and Van't Hoff's factor ,i, were calculated. Their values decrease with increasing dye concentration and increase with increasing temperature. The mobility, $\mu$, the activation energy, E, were also calculated. The findings indicate that interionic attractions and connections are present. Dye ions tend to selfassociate. Since these textile dyes were applied from aqueous systems, it is important to understand the association of dyes. The molecular aggregation of two sulphonated dyes studied by measuring the electrolytic conductivity in aqueous solutions as a function of dye concentration and temperature. Aggregation number, aggregation constant and shape of aggregate were calculated. As expected, the aggregation number decreases with increasing temperature, and that tends to J-aggregation which enhance the devices performance such as xerography, sensors, dye sensitized solar cells (DSSCs). In identifying new dyes for (DSSCs), multiple criteria such as broad absorption spectra, stable metal oxide binding and reduced aggregation of dye need to be considered.
\end{abstract}

Keywords: Electrolytic conductivity, Association, Acid dyes, Mordant dyes

\section{INTRODUCTION}

Sulphonated dyes are important industrial items that are commonly used. To improve their solubility in water, sulphonic groups are incorporated into dye molecules. The association of dyes, surfactants, drugs, etc. in aqueous solutions is of are absolutely essential in biological, colloid, surface, textile, photographic and analytical chemistry [1]. In the understanding and interpretation of a wide variety of problems, including fiber testing, tissue staining in biology, spectral change and energy transfer studies, adsorbing and photography, the self-association of the dye in aqueous solutions is significant. Often one of the most common instances of stacking behaviors is the dye association. Many dyes display significant association with $10^{-6}-10^{-4} \mathrm{M}$ concentrations and qualitative evidence of several studies indicates a number of multimers are produced [2,3]. There is great interest in dye aggregation and has been studied by many researchers [4-7].

For dye molecules, improvements in absorption and emissions properties of dye solutions were found over a century ago when the temperature variation changed and these improvements were correctly due to aggregation. Following the discovery of $\mathrm{J}$ aggregation, many efforts have been made to grasp the structural and spectral properties of dye aggregates and investigate the related phenomena in important technical fields, including photographic research [8].

Aggregation in small molecules has been shown to alter the shape of the absorption bands. This phenomenon has been used in organic photoconductive materials for xerography, sensors, dye sensitized solar cells (DSSCs). For (DSSCs) aggregation often reduces device efficiency. This is largely due to interaction dye-dye on the metal oxide surface (during sensitization) that the formation of aggregates $[9,10]$. These events in turn lead to shifts in the absorption spectrum compared the dye in solution. While H-aggregates lead to a hypsochromic/blue shift, J-aggregates results in bathochromic/red shift of the absorption spectra, J-aggregation can enhance the device performance (due to broadening of the absorption spectra), H-aggregation invariably lowers the light-harvesting capability. In identifying new dyes for (DSSCs), multiple criteria such as broad absorption spectra, stable metal oxide binding and reduced aggregation need to be considered [11,12]. 
Electrolytic conductivity is the most effective method for qualitative analyzes of the dyes aggregated phenomena according to the concentration which can help interionic attraction in the change in conduct with concentration in dilute solution [13-16].

Due to its significance in the environment and in diverse technologies, such as adsorption and calculating drift speed, the mobility of dyes was investigated which can be used to describe the ionic current density that is flowing through a solution[17]. Mobility has considered being a powerful feature to provide information on the size of fractional coefficients and is used for precipitation management successfully [18]. In the present work, electrolytic conductivity was used for the qualitative investigation of the aggregation of two azo dyes AR151 and MG17, in aqueous solution as a function of dye concentration and temperature. The degree of ionization, $\alpha$, and Van't Hoff's factor ,i, mobility, $\mu$, and the activation energy, $\mathrm{E}$, were also calculated. Perhaps this study is exploited and used these dyes to improve the efficiency of devices.

\section{2- MATERIALS AND METHODS}

Azo dyes, C.I. Acid Red 151 (AR151) scheme I and C.I. Mordant green 17 (MG17) scheme II, were obtained from ICI Company. The dyes were purified by recrystallization several times from $50 \%$ ethanol-water mixture and then dried in vacuum at $40^{\circ} \mathrm{C}$. Stock solution of dyes were prepared and left to attain equilibrium over night before use.

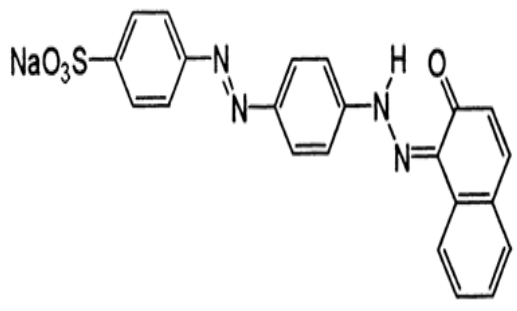

Scheme I

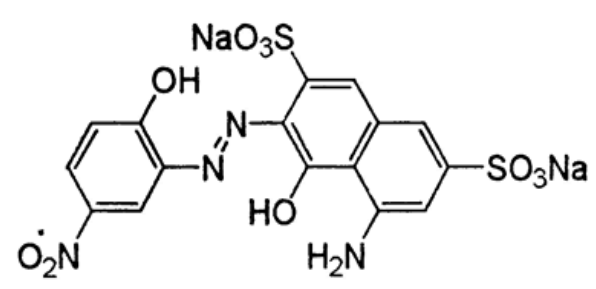

Scheme II
The Scheme I, represents the chemical structure of monosulphonic AR151, while Scheme I represents the chemical structure of disulphonic MG17 which is more soluble than the monosulphonic acid dye. The association of each dye in aqueous solution was estimated at different concentrations ranging from 1.2 to 49 $\mathrm{x} 10^{-4} \mathrm{gm} \mathrm{eq} \mathrm{l}^{-1}$ and at different temperatures $\left(15,20,25,30\right.$ and $\left.35^{\circ} \mathrm{C}\right)$, the solutions were prepared in doubly distilled water and had a conductivity $4 \times 10^{-6} \Omega^{-1} \mathrm{~cm}^{-1}$ at $25^{\circ} \mathrm{C}$. All solutions were thermostatic at the chosen temperatures in the range $t \pm 0.5^{\circ} \mathrm{C}$. The specific conductance were measured with a digital conductivity meter (Jenway 4010/REVC made in U.K.) and the conductivity cell was calibrated with $\mathrm{KCl}$ solution in the appropriate concentration range. The cell constant was 0.99 $\mathrm{cm}^{-1}$. The specific conductance measured under different concentrations and temperatures has been analyzed by Debye Hückel-Onsager theory of conductivity. These values have been used to compute the equivalent conductance, $\Lambda$ and the equivalent conductance at infinite dilution $\Lambda_{0}$. The ionic conductance of sodium ion used at infinite dilution at different temperatures was obtained from Glasston and Robinson[19,20]. At infinite dilution, the equivalent conductance of dye anions, $\lambda_{0}^{-}$, mobility, $\mu_{\mathrm{o}}$, and Van't Hoff's factor, $i$, were calculated. Also the aggregation number, N, aggregation constant $\mathrm{K}_{\mathrm{n}}$ of each dye and the energy of activation of rate process were determined [20,21].

\section{3- RESULTS AND DISCUSSION}

\section{1- conductivity, $k$}

The conductivity was measured for aqueous solutions of disulphonic acid dye AR 151 and disulphonic mordante dye MG17 at various concentrations (ranging from 1.2 to $49 \times 10^{-4}$ $\left.\mathrm{gm} \mathrm{eq} \mathrm{l}^{-1}\right)$ and different temperatures (15, $20,25,30$ and $35^{\circ} \mathrm{C}$ ) and the results are shown in Figures (1) and (2) respectively. Figures (1) and (2) suggest that the greater values of different conductance for MG17 are primarily due to disulphonic groups present in the high-charge dye molecule and ionizing groups surrounded by the presence of more counter ions. The plot of specific conductance, $k$, as a function of concentration for the two dyes at different 
temperatures indicated that $k$ increases sharply in the dilute solution with increasing color concentration. This behavior can be attributed to the increased ionization of the dyes into sodium ion and coloration anions.[22]

However, $k$ becomes almost linear over the higher range of concentrations greater than 6.2 x $10^{-4}$ and $16 \times 10^{-4} \mathrm{~g} \mathrm{eq}^{-1}$ for AR151 and MG17 respectively, Due to the extreme reciprocal attraction of different symbols ions surrounding the anion dye. A minor increase in conductivity $k$ can be attributed to a rise in entropy at higher concentrations of the two dyes resulting from melting of a 'ice-berg' structure around polar molecules. An experimental data indicates that the conductivity $k$ increases when the temperature increases Figures (1) and (2). It can be explained by increasing the effective degree of temperature ionization or by raising the limiting migration potential at an elevated temperature. The conductivity values for almost every concentration can be expressed by an excellent straight line. This allows the data to be interpreted by a straight-line formula for precise temperature behavior.[23]

$$
k=k_{o}(1+\mathrm{Bt})
$$

Where, $k_{o}$ and $\mathrm{B}$, are the conductivity at temperature $\left(25^{\circ} \mathrm{C}\right) \mathrm{t}_{\mathrm{o}}$ and the temperature coefficient of conductivity respectively. The values of $k_{o}$ and $\mathrm{B}$ at different concentrations for the two dyes are recorded in Table (1). This was done using the linear program to estimate the best straight line.

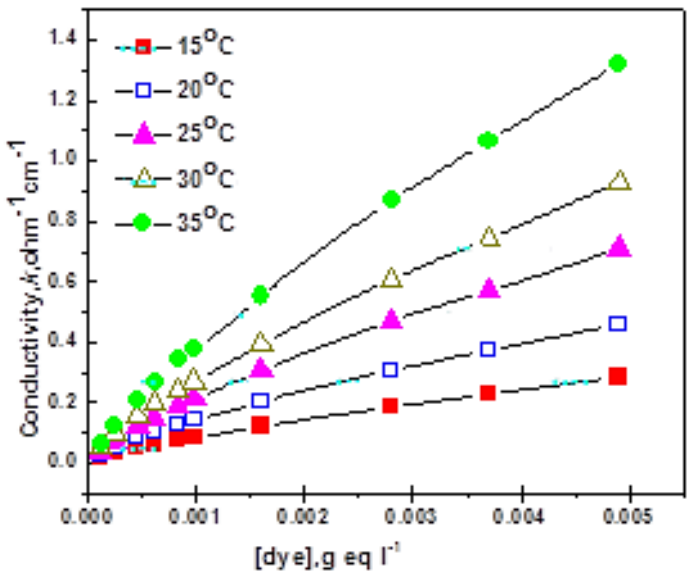

Fig.(1): Conductivity versus concentration of AR151 at different temperatures.

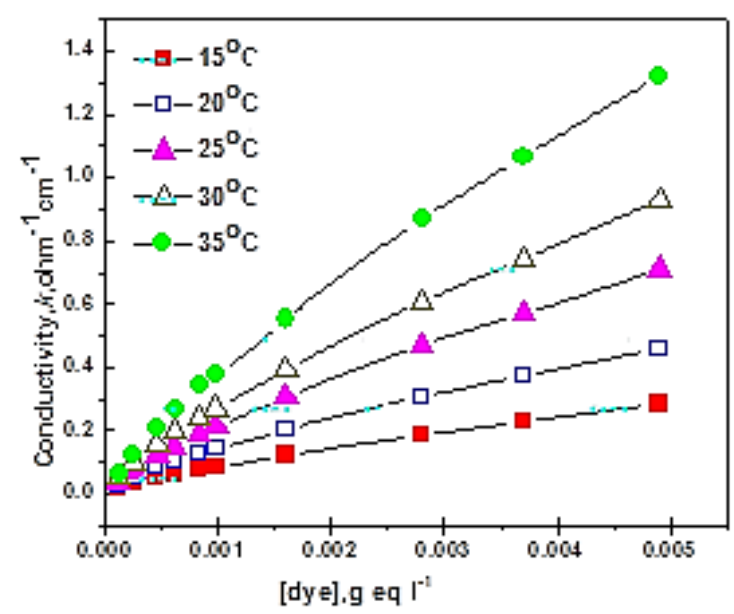

Fig.(2): Conductivity versus concentration of MG17at different temperatures.

Table (1): Conductivity, $k_{o}$, at temperature $t_{0}\left(25^{\circ} \mathrm{C}\right)$, and temperature coefficient of specific conductance, B, for AR 151 and MG17 dyes. $\left(R^{2}\right.$, The correlation coefficient)

\begin{tabular}{|c|c|c|c|c|c|c|}
\hline \multirow{2}{*}{$\begin{array}{c}{[\mathrm{dye}] \mathbf{x 1 0 ^ { 4 }}} \\
\operatorname{g~eq~}^{-1}\end{array}$} & \multicolumn{3}{|c|}{ AR 151} & \multicolumn{3}{|c|}{ MG 17} \\
\hline & $\begin{array}{c}k_{o}, \\
\Omega^{-1} \mathbf{c m}^{-1}\end{array}$ & B & $\mathbf{R}^{2}$ & $\begin{array}{c}k_{o}, \\
\Omega^{-1} \mathbf{c m}^{-1}\end{array}$ & B & $\mathbf{R}^{2}$ \\
\hline 1.2 & 6.0 & 0.173 & 0.990 & 18.1 & 0.129 & 0.998 \\
\hline 2.5 & 12.1 & 0.161 & 0.997 & 16.9 & 0.278 & 0.995 \\
\hline 4.6 & 20.1 & 0.136 & 0.998 & 26.0 & 0.304 & 0.993 \\
\hline 6.2 & 23.0 & 0.108 & 0.989 & 32.0 & 0.313 & 0.994 \\
\hline 8.4 & 24.0 & 0.163 & 0.971 & 34.0 & 0.376 & 0.991 \\
\hline 9.8 & 33.2 & 0.107 & 0.978 & 40.0 & 0.353 & 0.993 \\
\hline 16 & 42.2 & 0.094 & 0.973 & 53.0 & 0.396 & 0.991 \\
\hline 28 & 55.1 & 0.093 & 0.961 & 73.0 & 0.452 & 0.990 \\
\hline 37 & 70.3 & 0.087 & 0.952 & 77.0 & 0.531 & 0.989 \\
\hline 49 & 74.5 & 0.085 & 0.942 & 109.0 & 0.468 & 0.990 \\
\hline
\end{tabular}




\section{2- Equivalent Conductance, $\Lambda$}

Figures (3) and (4) give values of equivalent conductance to average temperatures for the two dyes studied in aqueous solutions. The results suggest an increase in dye concentration due to the effect of ion atmosphere solvation or a reduction in mobility and partial dissociation of the dye molecules [22]. The relations between equivalent conductance and concentration square root are shown in Figures (3) and (4) for AR151 and MG17 respectively. The curves exhibited a slowly fall of linearity for the two investigated dyes using concentrations higher than $6.2 \times 10^{-4}$ and $16 \mathrm{x}$ $10^{-4} \mathrm{~g} \mathrm{eq}^{-1}$ for AR151 and MG17, respectively. The increase in viscosity and the degree in dye aggregation or the limitation of motion of the counter-ions might well be due to this action [ 24]. An extrapolation into zero has been estimated for the equivalent behavior at infinitely dilution $\Lambda_{0}$, where a defined charged ion depends only on its nature and the interionic effect vanishes. The values of $\Lambda_{0}$ at varies temperatures are given in Tables (2) and (3) for AR151 and MG17 respectively. The higher mobility of ions due to high of thermal energy and the rupture of high hydrogen bonds enhances this with increasing temperature. The vibrational, rotational and translation energies also vary with temperature [25].The limiting conductance of anionic dye molecule, $\lambda_{\mathrm{o}}^{-}$, is obtained by subtracting the limiting conductance of sodium ion, $\lambda^{+}$, at different temperatures from the equivalent conductance at infinite dilution.

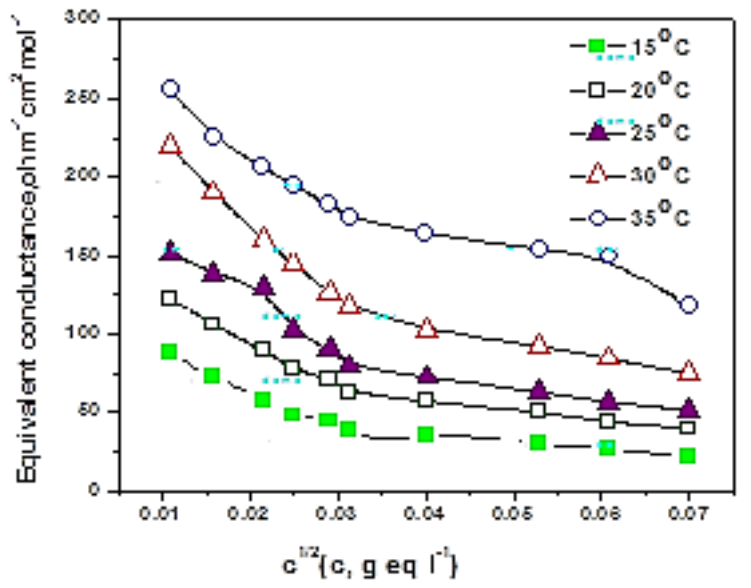

Fig.(3): Equivalent conductance versus concentration of AR151 at different temperatures.

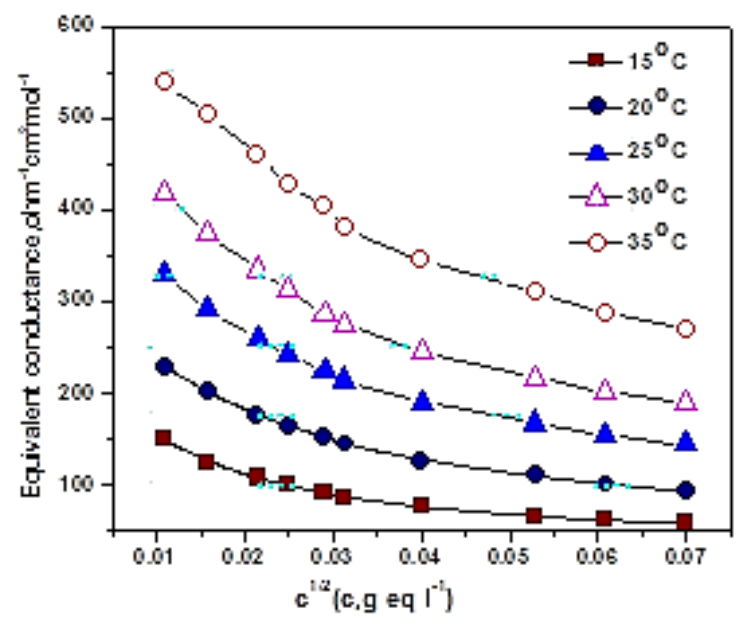

Fig.(4): Equivalent conductance versus concentration of MG17 at different temperatures.

Table (2): Equivalent conductance at infinite dilution , $\Lambda_{0}$, limiting conductance of dye anion, $\lambda_{0}^{-}$, dye anion mobility, $\mu_{0}$, aggregation number, $N$, shape of aggregates ,a, and energy of activation $E$, at infinite dilution and different temperatures for AR 151

\begin{tabular}{|c|c|c|c|c|c|c|}
\hline $\mathbf{t}^{0} \mathbf{C}$ & $\begin{array}{c}\Lambda_{0} \\
\Omega^{-1} \mathrm{~cm}^{2} \mathbf{e q} \mathbf{l}^{-1}\end{array}$ & $\begin{array}{c}\lambda_{\mathbf{0}} \\
\Omega^{-1} \mathrm{~cm}^{2} \text { eq } \mathbf{l}^{-1}\end{array}$ & $\begin{array}{c}\mu_{0}, \mathbf{x} 10^{3} \\
\mathrm{~cm}^{2} \mathbf{v}^{-1} \mathbf{s}^{-1}\end{array}$ & $\mathbf{N}$ & $\begin{array}{c}\text { Shape of } \\
\text { agg. a }\end{array}$ & $\mathbf{E}, \mathbf{k J} . \mathbf{m o l}^{-1}$ \\
\hline 15 & 110 & 70 & 0.57 & 6.28 & \multirow{5}{*}{1.99} & \multirow{5}{*}{37.32} \\
\hline 20 & 160 & 114 & 0.83 & 5.88 & & \\
\hline 25 & 200 & 149 & 1.04 & 4.39 & & \\
\hline 30 & 260 & 202.5 & 1.35 & 3.35 & & \\
\hline 35 & 305 & 242.5 & 1.58 & 2.42 & & \\
\hline
\end{tabular}


Table (3): Equivalent conductance at infinite dilution, $\Lambda_{0}$, limiting conductance of dye anion, $\lambda^{-}$, dye anion mobility, $\mu_{0}$, aggregation number, $N$, shape of aggregates ,a, and energy of activation, $E$, at infinite dilution and different temperatures for MG17.

\begin{tabular}{|c|c|c|c|c|c|c|}
\hline $\mathbf{t}^{0} \mathbf{C}$ & $\begin{array}{c}\Lambda_{0}, \\
\Omega^{-1} \mathbf{c m}^{2} \text { eq } \mathbf{l}^{-1} \\
\end{array}$ & $\begin{array}{c}\lambda_{\mathrm{o}}^{-}, \\
\Omega^{-1} \mathrm{~cm}^{2} \text { eq } \mathbf{l}^{-1}\end{array}$ & $\begin{array}{c}\mu_{0}, \mathbf{x} 10^{3} \\
\mathrm{~cm}^{2} v^{-1} s^{-1} \\
\end{array}$ & $\mathbf{N}$ & $\begin{array}{c}\text { Shape of } \\
\text { agg. a }\end{array}$ & $\mathrm{E}, \mathrm{KJmol}^{-1}$ \\
\hline 15 & 198.09 & 158.09 & 0.68 & 5.34 & \multirow{5}{*}{1.82} & \multirow{5}{*}{40.35} \\
\hline 20 & 310.73 & 264.73 & 1.07 & 4.75 & & \\
\hline 25 & 420.67 & 369.67 & 1.45 & 3.01 & & \\
\hline 30 & 510.79 & 453.29 & 1.76 & 1.46 & & \\
\hline 35 & 603.60 & 541.10 & 2.08 & 0.89 & & \\
\hline
\end{tabular}

3.3- Mobility of dye anion and Vant Hoff's factor:

The most important characteristic of ions is mobility, $\mu_{o}$, that reveals their specific participation in an electrolyte's electric conductance. The mobility's of anionic dye molecule at different temperatures were obtained from the relation:

$$
\mu_{\mathrm{o}}=\Lambda_{\mathrm{o}} \mathrm{zF}
$$

Tables (2) and (3) indicate that the mobilities of AR151 (M.wt.= 454.43)anions are higher than those of MG17 $(\mathrm{M} . \mathrm{wt}=528.38)$ since the former has a low M.wt. than the latter. Further, the lower mobility MG17 may be due to the presence of groups of donors and acceptors [26]. This is due to the disaggregation and variation in the intermolecular bonding.

The values of Vant Hoff's factor, i , were determined for the two dyes under studies and computed from the relation:

$$
\mathrm{i}=\alpha(\mathrm{v}-1)+1
$$

Where $\mathrm{v}$ is the number of ions and $\alpha$ ionization degree at variable concentrations and temperatures were estimated as discussed previous studies [20,21]. Tables (4) and (5) indicate that the values of Vant Hoff's factor, i, decrease as in the concentration of dye increasingly suggesting ionization and repugnance among ionic species.

\section{4-Rate of activation energy}

Energy of activation for conductance process can be calculated by applying the relation [25]: $\log \Lambda_{\mathrm{o}}=\log \mathrm{A}-\mathrm{E} / 2.303 \mathrm{RT}$

Where, $\mathrm{A}$ is a constant and $\mathrm{E}$ is the energy of activation for rate process. From the plot of $\log \Lambda_{\mathrm{o}}$ in aqueous media vs. $1 / \mathrm{T}$ the activation energy was computed from the slope. The data obtained reported the average activation energies of ionic migration of 37.32 and 40.35 $\mathrm{KJmol}^{-1}$ for AR151 and MG17 dyes respectively.

\section{5- Aggregation number, Aggregation} constant and Shape of aggregates

The variation of equivalent conductance with the square root of equivalent concentration of aqueous dye solutions show that the equivalent conductance decreases with increasing the dye concentration. The results suggest that the dye molecules interact and tend to be aggregated [27]. The average of aggregation number $\mathrm{N}$ at different dye concentrations and at different temperatures was calculated using the method reported by Holmes and standing [28], the equation in the form:

$$
\mathrm{N}=0.852(\mathrm{M} / \rho)^{1 / 2}(\eta / \mathrm{zF})^{3 / 2}\left(\Lambda^{\circ} / \mathrm{F}-\mathrm{Lg}\right)^{3 / 2}
$$

Where 0.852 is the value collected the universal constants, $\mathrm{M}$ is the molecular weight of the ions, $\rho$ is the micelle density, $\eta$ is the viscosity of the medium, $\mathrm{z}$ is the charge carried by the dye ion, $\Lambda^{\circ}$ is the equivalent conductance of the dye at infinite dilution, $\mathrm{Lg}$ is the ionic conductance of the gegenions which may be $\mathrm{Na}^{+}, \mathrm{H}^{+}$or others and $\mathbf{F}$ is the fraction of the total gegenion that are not included in the micelle. 
Table (4) :Calculation the Vant Hoff's factor ,i, degree of ionization, $\alpha$, and aggregation constant, $K_{n}$, at different concentrations and temperatures for C.I. Acid Red 151(AR151) in aqueous solution.

\begin{tabular}{|c|c|c|c|c|c|c|c|c|}
\hline \multirow{2}{*}{$\begin{array}{c}{\left[\text { dye] } x^{10^{4}} \mathrm{~g}\right.} \\
{\text { eq } \mathrm{I}^{-1}}^{-1}\end{array}$} & \multicolumn{4}{|c|}{$15^{\circ} \mathrm{C}$} & \multicolumn{4}{|c|}{$20^{\circ} \mathrm{C}$} \\
\hline & $\begin{array}{c}\Lambda, \\
\Omega^{-1} \mathrm{~cm}^{2} \text { eq } \mathrm{l}^{-1}\end{array}$ & A & I & $K_{n} \cdot 10^{-3}$ & $\begin{array}{c}\Lambda, \\
\Omega^{-1} \mathbf{c m}^{2} \text { eq } \mathbf{l}^{-1}\end{array}$ & $\alpha$ & I & $K_{n} \cdot 10^{-3}$ \\
\hline 1.2 & 82.8 & 0.80 & 1.80 & 2.40 & 122.11 & 0.86 & 1.76 & 2.24 \\
\hline 2.5 & 71.3 & 0.66 & 1.66 & 2.50 & 105.66 & 0.66 & 1.66 & 2.32 \\
\hline 4.6 & 57.98 & 0.53 & 1.53 & 3.18 & 89.78 & 0.56 & 1.56 & 2.62 \\
\hline 6.2 & 47.80 & 0.43 & 1.43 & 4.54 & 77.55 & 0.48 & 1.48 & 3.32 \\
\hline 8.4 & 44.56 & 0.41 & 1.41 & 4.51 & 71.36 & 0.45 & 1.45 & 3.48 \\
\hline 9.8 & 38.26 & 0.35 & 1.35 & 6.07 & 62.24 & 0.39 & 1.39 & 4.9 \\
\hline 16 & 34.87 & 0.32 & 1.32 & 5.84 & 57.03 & 0.36 & 1.36 & 4.40 \\
\hline 28 & 29.88 & 0.27 & 1.27 & 6.75 & 50.1 & 0.31 & 1.31 & 4.81 \\
\hline 37 & 26.48 & 0.24 & 1.24 & 8.30 & 43.66 & 0.27 & 1.27 & 6.24 \\
\hline 49 & 21.22 & 0.19 & 1.19 & 13.04 & 39.45 & 0.25 & 1.25 & 7.52 \\
\hline
\end{tabular}

Table (4): Cont'd

\begin{tabular}{|c|c|c|c|c|c|c|c|c|c|c|c|c|}
\hline \multirow{2}{*}{$\begin{array}{c}{[\text { dye] }} \\
10^{4} \\
\mathrm{~g} \mathrm{eq} \\
\mathrm{l}^{-1}\end{array}$} & \multicolumn{4}{|c|}{$25^{\circ} \mathrm{C}$} & \multicolumn{4}{|c|}{$30^{\circ} \mathrm{C}$} & \multicolumn{4}{|c|}{$3^{\circ} \mathrm{C}$} \\
\hline & $\begin{array}{c}\Lambda, \\
\Omega^{-1} \mathbf{c m}^{2} \\
\text { eq }^{-1}\end{array}$ & A & I & $\begin{array}{c}K_{\mathbf{n}} \\
10^{-3}\end{array}$ & $\begin{array}{c}\Lambda, \\
\Omega^{-1} \mathbf{c m}^{2} \\
\text { eq l }^{-1}\end{array}$ & A & I & $\begin{array}{c}\mathbf{K}_{\mathbf{n}} \\
\mathbf{1 0}^{-3}\end{array}$ & $\begin{array}{c}\Lambda, \\
\Omega^{-1} \mathbf{c m}^{2} \\
\text { eq } \mathbf{l}^{-1}\end{array}$ & A & I & $K_{n} 10^{-3}$ \\
\hline 1.2 & 159.00 & 0.80 & 1.80 & 1.79 & 219.24 & 0.84 & 1.84 & 1.21 & 255.42 & 0.84 & 1.83 & 1.28 \\
\hline 2.5 & 138.44 & 0.69 & 1.69 & 1.91 & 190.01 & 0.73 & 1.73 & 1.54 & 224.68 & 0.74 & 1.74 & 1.48 \\
\hline 4.6 & 130.00 & 0.65 & 1.65 & 1.56 & 160.03 & 0.62 & 1.62 & 1.91 & 206.23 & 0.68 & 1.68 & 1.33 \\
\hline 6.2 & 101.52 & 0.51 & 1.51 & 2.89 & 144.22 & 0.55 & 1.55 & 2.25 & 194.56 & 0.64 & 1.64 & 1.3 \\
\hline 8.4 & 90.23 & 0.45 & 1.45 & 3.37 & 126.57 & 0.49 & 1.49 & 2.71 & 182.43 & 0.60 & 1.60 & 1.40 \\
\hline 9.8 & 79.12 & 0.40 & 1.40 & 4.39 & 117.87 & 0.45 & 1.45 & 3.02 & 174.05 & 0.57 & 1.57 & 1.50 \\
\hline 16 & 72.35 & 0.36 & 1.36 & 4.23 & 102.23 & 0.39 & 1.39 & 3.52 & 163.55 & 0.54 & 1.54 & 1.45 \\
\hline 28 & 63.11 & 0.32 & 1.32 & 4.72 & 92.22 & 0.35 & 1.35 & 3.66 & 153.96 & 0.51 & 1.50 & 1.39 \\
\hline 37 & 56.44 & 0.28 & 1.28 & 5.76 & 84.32 & 0.32 & 1.32 & 4.29 & 148.87 & 0.49 & 1.49 & 1.43 \\
\hline 49 & 51.42 & 0.26 & 1.25 & 6.82 & 74.55 & 0.29 & 1.29 & 5.53 & 117.52 & 0.39 & 1.39 & 2.64 \\
\hline
\end{tabular}

Table ( 5 ) : Calculation the Vant Hoff's factor ,i, degree of ionization, $\alpha$, and aggregation constant, $K_{n}$, at different concentrations and temperatures for C.I. Mordant Green 17 (MG17) in aqueous solution.

\begin{tabular}{|c|c|c|c|c|c|c|c|c|}
\hline \multirow[b]{2}{*}{$\begin{array}{c}{[\text { dye }]} \\
\times 10^{4} \mathrm{~g} \mathrm{eq}^{-1}\end{array}$} & \multicolumn{4}{|c|}{$15^{\circ} \mathrm{C}$} & \multicolumn{4}{|c|}{$20^{\circ} \mathrm{C}$} \\
\hline & $\begin{array}{c}\Lambda \\
\Omega^{-1} \mathrm{~cm}^{2} \text { eq } \mathbf{l}^{-1}\end{array}$ & $\mathbf{A}$ & I & $\begin{array}{c}\mathbf{K}_{\mathbf{n}} \\
\mathbf{x 1 0 ^ { - 3 }}\end{array}$ & $\begin{array}{c}\Lambda, \\
\Omega^{-1} \mathrm{~cm}^{2} \mathbf{e q} \\
\mathbf{l}^{-1}\end{array}$ & $\mathbf{A}$ & i & $K_{n} \times 10^{-3}$ \\
\hline 1.2 & 150 & 0.78 & 2.57 & 1.18 & 230 & 0.82 & 2.63 & 0.92 \\
\hline 2.5 & 125 & 0.65 & 2.31 & 1.40 & 201 & 0.71 & 2.43 & 0.97 \\
\hline 4.6 & 108 & 0.56 & 2.13 & 1.43 & 177 & 0.63 & 2.26 & 0.98 \\
\hline 6.2 & 100 & 0.52 & 2.04 & 1.44 & 165 & 0.59 & 2.17 & 0.99 \\
\hline 8.4 & 92 & 0.48 & 1.96 & 1.46 & 153 & 0.54 & 2.09 & 1.01 \\
\hline 9.8 & 87 & 0.45 & 1.91 & 1.54 & 145 & 0.51 & 2.03 & 1.06 \\
\hline 16 & 76 & 0.40 & 1.79 & 1.58 & 127 & 0.45 & 1.90 & 1.11 \\
\hline 28 & 66 & 0.34 & 1.69 & 1.62 & 110 & 0.39 & 1.78 & 1.17 \\
\hline 37 & 62 & 0.32 & 1.65 & 1.64 & 101 & 0.36 & 1.72 & 1.26 \\
\hline 49 & 58 & 0.30 & 1.61 & 1.70 & 94 & 0.33 & 1.67 & 1.33 \\
\hline
\end{tabular}


Table (5): Cont'd

\begin{tabular}{|c|c|c|c|c|c|c|c|c|c|c|c|c|}
\hline \multirow[b]{2}{*}{$\begin{array}{c}{[\text { dye }]} \\
10^{4} \mathrm{~g} \mathrm{eq} \\
\mathrm{l}^{-1}\end{array}$} & \multicolumn{4}{|c|}{$25^{\circ} \mathrm{C}$} & \multicolumn{4}{|c|}{$30^{\circ} \mathrm{C}$} & \multicolumn{4}{|c|}{$35^{\circ} \mathrm{C}$} \\
\hline & $\begin{array}{c}\Lambda, \\
\Omega^{-1} \mathrm{~cm}^{2} \\
\mathbf{e q ~ \mathbf { l } ^ { - 1 }}\end{array}$ & $\alpha$ & I & $\begin{array}{c}K_{n} \\
10^{-3}\end{array}$ & $\begin{array}{ll}\Lambda, & \Omega \\
\mathrm{cm}^{2} \mathbf{e q} & \mathbf{1} \\
& 1\end{array}$ & A & i & $\begin{array}{c}K_{n} \\
10^{-3}\end{array}$ & $\begin{array}{c}\Lambda, \\
\Omega^{-1} \mathrm{~cm}^{2} \\
\text { eq } \mathbf{l}^{-1}\end{array}$ & $\mathbf{A}$ & I & $\begin{array}{c}K_{n} \\
10^{-3}\end{array}$ \\
\hline 1.2 & 330 & 84 & 2.68 & 0.75 & 420 & 0.86 & 2.73 & 0.62 & 540 & 0.93 & 2.86 & 0.41 \\
\hline 2.5 & 292 & 0.74 & 2.49 & 0.79 & 375 & 0.77 & 2.54 & 0.67 & 505 & 0.87 & 2.73 & 0.45 \\
\hline 4.6 & 260 & 0.66 & 2.33 & 0.80 & 335 & 0.69 & 2.38 & 0.69 & 460 & 0.79 & 2.58 & 0.52 \\
\hline 6.2 & 242 & 62 & 2.23 & 0.83 & 314 & 0.65 & 2.29 & 0.70 & 430 & 0.748 & 2.48 & 0.59 \\
\hline 8.4 & 224 & 0.57 & 2.14 & 0.86 & 287 & 0.59 & 2.18 & 0.77 & 405 & 0.70 & 2.39 & 0.61 \\
\hline 9.8 & 215 & 5 & 2.10 & 0.87 & 275 & 0.57 & 2.13 & 0.79 & 382 & 0.66 & 2.31 & 0.69 \\
\hline 16 & 191 & 0.48 & 1.97 & 0.89 & 245 & 0.50 & 2.01 & 0.81 & 345 & 0.59 & 2.19 & 0.71 \\
\hline 28 & 168 & 0.42 & 1.85 & 0.91 & 217 & 0.45 & 1.89 & 0.82 & 310 & 0.53 & 2.07 & 0.72 \\
\hline 37 & 154 & 0.39 & 1.78 & 0.99 & 201 & 0.41 & 1.83 & 0.87 & 288 & 0.50 & 1.99 & 0.78 \\
\hline 49 & 145 & 0.37 & 1.73 & 1.03 & 190 & 0.39 & 1.78 & 0.89 & 270 & 0.46 & 1.92 & 0.83 \\
\hline
\end{tabular}

Tables (2) and (3) show the values of average aggregation number $\mathrm{N}$ of the two dyes in aqueous solutions at different temperatures. The result showed that the aggregation number decreases with increasing temperatures. It indicates also the endothermic nature of the dissociation process of the two dyes under investigation. Since the MG17 has less aggregation number than AR151.These results confirmed to J-aggregation which enhance the device performance in presence of metal oxide $[11,12]$.

Quantitative aggregation constant $\mathrm{K}_{\mathrm{n}}$ for each set of values of dyes concentrations at different temperatures was calculated according to Walter [29]. The calculated values of aggregation constant at different temperatures for the two investigated dyes are collected in Tables (4) and (5). The results indicated, the higher values of aggregation constant for MG17 than those of AR151.This is due to the presence of donating groups such as hydroxide, amino and nitro groups in MG17 dye, these groups create a residual negative charge on the molecule, in addition to the sulphonic group in the aromatic ring. The values of aggregation constant increase with increasing dye concentration and decrease with increasing temperature which confirm the disaggregating effect of temperature.

The shape of aggregate of two dyes can be determined from the following equation:

$$
[\eta]=\mathrm{K}_{\mathrm{n}} \mathrm{M}^{\mathrm{a}}
$$

The plot of the logarithm of the intrinsic viscosity [ $\eta]$ of the dye at different temperatures against the logarithm of the molecular weight, $\mathrm{M}$, gave a straight line with slope equal to "a" and $\mathrm{K}_{\mathrm{n}}$ is a constant for a given solute-solvent system. From the results obtained "a" has the values of 1.99 and 1.82 for AR151 and MG17 dyes respectively. The results indicated that the aggregate forms of the two dyes are spherical due to that the values of "a" higher than unity [30].

\section{CONCLUSION}

Electrolytic conductivity has been used to study the association of AR151 and MG 17 in aqueous solutions.

Different physical parameters as mobility, $\mu_{\mathrm{o}}$, Van't Hoffs factors, $i$, aggregation number $\mathrm{N}$, aggregation constant $\mathrm{K}_{\mathrm{n}}$ and shape of aggregate "a" were computed.

All the previous physical parameters depend on the concentration of dye solution and temperature.

The results of the present investigation indicated that the physical parameters depend on withdrawing effect the number of sulphonic groups, which also affect the dye association. The results obtained confirm that, the two dyes used tend to J-aggregation which enhance the device performance. 


\section{REFERENCES}

[1] Dakiky M., Nemcova I., Dyes Pigm., 40 (1999) 141.

[2] Mukerjee P., Ghosh A. K., J. Am. Chem. Soc., 92 (1970) 6403.

[3] Ghasemi J.,B., Miladi M., J. Chin. Chem. Soc. 56,2009$), 459$.

[4] Inglesby M.K., Zeronian S.H., Cellulose, 2 (2002), 19.

[5] Horowitz V.R., Janowitz L.A., Modic A.L., Heiney P.A., Collings, P.J. Physical Review E., 72 (2005), 41710-1- 41710-10

[6] Ghasemi J., Niazi A., Westman G.,Kubista M., Talanta, 62(4), (2004), 835.

[7] Ali N., Ateesa Y., Jahanbakhsh G., Mikael K., Spectrochimica Acta Part A, 65, (2006) ,73-78.

[8] Shapovalov S. A., Modern Organic Chemistry Research, 2( 4), ( 2017).

[9] Hestand N.J., Spano F.C., Chem. Rev., 118, (2018), 7069-7163.

[10] Zhang L., Cole J.M., J. Mater.Chem. A, 5, (2017), 19541-19559.

[11] Vishwesh V., Lethesh K. C., Data , 5 (45), (2020).

[12] Venkatraman V., Yemene A.E., de Mello, Sci. Rep. 9 , (2019) .

[13] El- Mariah, Afaf A.R. and El-Sabbagh I.E., Indian Textile J., 1,(1975),147.

[14] Tawarah K.M. , Wazwaz A.A., J. Dyes Pigm., 21(2),(1993), 97.

[15] Hui LU. and Leaist D.G., J. Solution Chem., 19(4), (1990), 391.

[16] Hidetaka O. and Akira K., J.S.D.C.,111,(1995), 311.

[17] Gerasimov Y.A, Dreving V.,Eremin E.,Kiselev A., Lebedev V., Physical Chemistry ,Mir publishers Moscow, (1978), 404.

[18] Meenkshi S. ,Anil K., Shire Y., Prasad B.B, J.Can.Chem.,75,(1997),414.

[19] Glasstone S.S., An introduction to Electrochemistry $4^{\text {th }}$ Ed. Van Nostrand, New York (1949)322.

[20] Robinson R.A., Stokes R.H., Electrolyte Solution, $2^{\text {th }}$ Butter Worth's, (1959), 465.

[21] Yadav M.S., Electrochemistry, First Edition Darya Ganj. New Delahi (1990),141 and 183.

[22] Mehrotrotra K.N., Kirti T. and Rawat M.K., J. Indian Chem. Soc.,67,(1990),719.
[23] Antropovl, Theoretical Electrochemistry Mir, publishers Moscow, (1977),128.

[24] Austen A.O., Imrie C.T., Ingram M.D., J. Polymer International, 47 (1),(1998),9.

[25] Ishwara J.B., Bindu P., J. Indian Chem.Soc., 72,(1995),783.

[26] Tameev A. R., Kozlov A. A., Vannikov A.V., J. Polymer International, 47(2),(1998), 198.

[27] Das S. and Prashant K., J. physical Chem B, 103, (1999), 209-214.

[28] Holmes F.H, Standing H.A.,Transaction Faraday Soc.,41,(1945),542.

[29] Walter J. M., "Physical Chemistry" Longman Group Ltd., London, (1972).

[30] Glasstone, S." Textbook of Physical Chemistry", $2^{\text {nd }} E d .$, London, (1951).

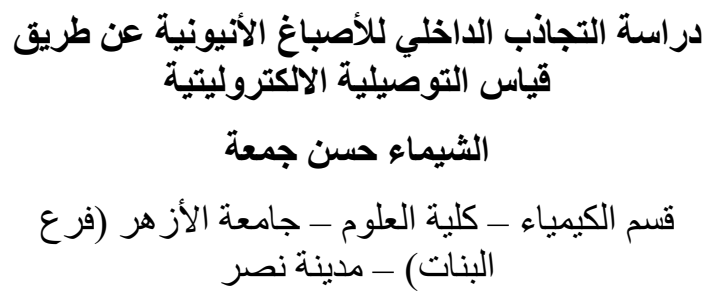
المحاليل المائية كدالة لتركيز الصبغة ودئة ودرجة الحرارة.

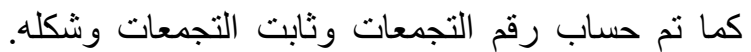
وكما هو متوقع انخفاض رقم التجمعات مع زيادة درجة التهات الحرارة .وبذللك يميل الي التجمعات الجزيئية-j الذي زئي يعزز أداء الاجهزة مثل التصوير بالاشعة السينية , اجهزة

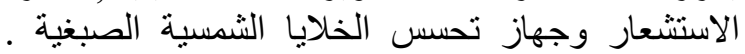

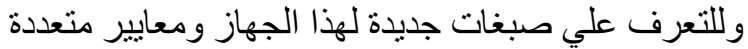
مثل اطياف أُمتصاص واسعة يجب مر اعاة تر ابط اكسيد الفلز المستقر وتقليل تجمعات جزيئات الصبغة. 